\title{
Transliteration System For Nepali Language
}

\author{
Suresh Man Shrestha, \\ Project Chief, \\ National Geographic Information Infrastructure Project, NGIIP, Survey Department, Nepal.
}

\section{Keywords}

Geographical names, Romanization, Transliteration, Barhakhari, Vowels, Consonants.

\begin{abstract}
:
Maps are one of the most popular and comprehensive documents in which people can see geographical names and are one of the most effective means to convey accurate place names. In absence of these names it would be very hard to relate the map with the ground. It is very important to standardize these names to get rid of confusion, inconsistency, uncertainty and misunderstanding the names presented in a map. It is rational to develop a Romanization (Transliteration) System for Nepali, not only to support the initiatives of United Nations Group of Experts on Geographical Names (UNGEGN) but also to standardize the way the Nepali geographical names are written especially in maps.
\end{abstract}

\section{INTRODUCTION}

As the Surveyors and Photogrammetrists wrap up their data capturing works, it is time for Cartographers to roll up their sleeves to present the captured data in a meaningful way in a form of map. The world we live on is full of different kinds of man-made and natural features like settlements, parks, transportation network, administrative units, hydrographic features, mountain range, peaks, forests etcetera. Most of the data are presented using traditional symbols. For example, blue lines for streams, rivers, canals; brown lines for contour lines; green color for features related to vegetation and so on.

Apart from the symbols assigned for different features, most of the features shown in a map have their own names viz. names of rivers, settlements, highways, country and administrative divisions and so on. Each of these features is identified by its name to make it distinct from others. It would have been wonderful to have unique and standard name for each and every geographical entities. But in practice we can see different names for one and same object, one name given for different objects lying in different geographical locations, same name written and spelled differently. It is very important to standardize these identifying names to get rid of confusion, inconsistency, uncertainty and misunderstanding of these features. It is more so when people from a different community or nation use these feature names.

Names of the geographical features should be unique as far as possible for consistent use and it is an essential element of communication worldwide and supports socioeconomic development of the concerned area. Due to script differences it has always been a problem to write proper feature names in a different language. For example, the name Kathmandu can be found written differently in different maps published by Survey Department. In topographic map at scale 1:25 000 , it is written as "KĀṬMĀNDAUU", in English version of map of Nepal at scale 1:1000 000, it is written as "KĀṬMMĀNDUU". The same name is written differently in Nepali version of map of Nepal at scale 1:1000 000 as "काठमाडौ" and "काठमाण्डौ". Following the pronunciation guide in map of Nepal at scale 1:1000 000, the name "KĀṬHMĀNḌU" should be written as "काठमान्डु" in Nepali script. Now the question arises whether all these three places "काठमाडौं", "काठमाण्डौ" and "काठमान्डु" the name for same place or names of three different places? This shows how important it is how to write names in maps? Will it not be possible for Survey Department to standardize those names at least in its own publications? Being a National Mapping Authority, Survey Department should find a way out for standardization of geographical names in Nepal. It is not an easy task. The gravity of this problem is so big that United Nations Organization has formed "Working Group on Romanization System" under "United Nations Group of Experts on Geographical Names (UNGEGN)".

The aim of this article is to raise awareness among the users of Nepali geographical names on how to write these names using roman alphabets and to get feedback from the readers of this article to develop/reorganize/ standardize Romanization (Transliteration) System for Nepali alphabets, especially to write geographical names. 


\section{MAP AND GEOGRAPHICAL NAMES}

Maps are one of the most popular and comprehensive documents in which people can see geographical names and are one of the most effective means to convey accurate place names. For general map users it is next to impossible to relate the map with the ground in absence of these names. In a map one can see a variety of geographical names viz. names of country and its administrative divisions, names of different places, roads, streets, rivers, mountain ranges, peaks and names of other natural and man-made features. The volume of these names in a map depends upon its type and map scale.

With the help of standard geographical names we can correctly and unanimously identify the reference location which plays a vital role in writing laws, regulations, legal notices postal addresses and other official documents. Standard geographical names are equally important in the field of education, tourism, administration, management, industry, commerce. Similarly, the role of standard geographical names is invaluable in the field of rescue operation, postal and transportation services. In the field of Geographical Information System (GIS), standard geographical names can be used as reference to which other attribute information can be linked.

Collecting all geographical names of a country and standardize them is not an easy task. There are many issues in standardizing geographical names. To collect, process, formalize and enforce the geographical names a "Geographical Names Authority" must be established. This will be the national authority in the field of geographical names. One of the biggest problems of standardization of place-names is the representation of geographical names in different alphabets and scripts. Since there is rarely a one-to-one relationship between the symbols of different alphabets, the risk of misrepresentation of geographical names from unsystematic conversion systems is imminent.

To coordinate the efforts of different countries in the field of geographical names, in 1959, the Economic and Social Council (ECOSOC) paved the way for a small group of experts to meet and provide technical recommendations on standardizing geographical names at the national and international levels. This meeting gave rise to the United Nations Conferences on the Standardization of Geographical Names (UNCSGN) and to the United Nations Group of Experts on Geographical Names (UNGEGN).

One of the general aims of UNGEGN has been to arrive at an agreement on a single, scientifically based, Romanization system from each non-Roman alphabet or script for international application. To aid the process, a special working group under the responsibility of the United Nations Permanent Committee of Experts on Geographical Names was set up - "Working Group on Romanization Systems".

\section{TRANSLITERATION}

According to Wikipedia Transliteration may be understood as a mapping from one system of writing into another, word by word, or ideally letter by letter. Transliteration attempts to use a one-to-one correspondence and be exact, so that an informed reader should be able to reconstruct the original spelling of unknown transliterated words.

The Roman writing system has 26 letters (a, b, c, d, e, f, g, h, i, j, k, l, m, n, o, p, q, r, s, t, u, v, w, x, y, z) as its core alphabet. These 26 letters are not sufficient to represent different letters and/or sounds from other languages. Diacritical marks, appearing above or below a letter, or in some other position such as within the letter or between two letters, are used to change the way these letters are pronounced. In this way letters/sounds from different languages can be represented in Roman system.

\section{NEPALI LANGUAGE}

Nepali is the official language of Nepal. It is an IndoAryan language spoken in Nepal, Bhutan, Burma and India. It is written in the Devanagari script. In Nepalese context it consists of 12 vowels, 36 consonants and some especial characters.

Nepali vowels: Practically 12 vowels are in common use as listed below:

अ आ इ ई उ ए ऐ ओ औ अं अ:

Apart from the above list of vowels, frequently the following vowels are also used in Nepali:

\section{ॠ ॠ लृ क्छ}

Nepali consonants:

In Nepali language there are 36 consonants. Each consonant is pronounced with a vowel sound अ (a) and are written as shown in the table below.

क ख ग घ च छ ज क ज

ट ठ ड ढ ण तथ द ध न

प फ ब भ म य ल व

श ष स ह क्ष त्र ज्ञ

Each consonant can also be pronounced without a vowel sound अ (a) and are written as shown below.

क् ख् ग् घ् च् छ् ज् भ् ज्

ट् ठठ ड् ढ् ण् त् थ् द् ध् न्

प् फ् ब् भ् म् य् र् व्

श् ष् स् ह् क्ष् त्र् ज्ञ

Extra letters - There are some especial letters in Nepali language as shown below.

श्र हृ ॐँ अँ 
Nepali numbers - The numeric digits from 0 to 9 are written in Nepali as follows.

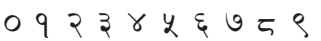

Combination of consonants and vowels creates different sounds in Nepali and are called Barhakhari. The following table illustrates the Barhakhari:

क का कि की कु कू के कै को कौ कं क:

ख खा खि खी खु खे खै खो खौ खं

ग गा गि गी गु ग गे गै गो गौ गं ग:

घ घा घि घी घु घू घे घै घो घौ घं घ:

and so on.

\section{TRANSLITERATION OF NEPALI LANGUAGE}

Over the past several decades several methods have been devised to convert Devanagari script to the Roman alphabetic script. The United Nations recommended system was approved in 1972 based on a report prepared by D. N. Sharma. United States Board on Geographic Names (BGN) and the Permanent Committee on Geographical Names for British Official Use (PCGN) have developed a Romanization system for Nepali in 1964 "The BGN/PCGN 1964 System". During the preparation of topographical maps of Lumbini Zone during 1980s and recent topographical maps during 1990s, Survey Department has developed Transliteration System for Nepali.

It is not possible to represent all Nepali letters with the help of just 26 Roman alphabets. Finding appropriate letters to represent Nepali vowels and consonants is the main task of developing a Transliteration (Romanization) system for Nepali. To represent different Nepali letters by Roman alphabets, we have to use combination of two or more Roman letters. Similarly we can use diacritic (a special mark added to a letter to indicate a different pronunciation, stress, tone, or meaning) marks as well. The following tables show the Roman letter (or letters) representing Nepali vowels and consonants:

Transliteration (Romanization) of Nepali vowels:

अ आ इ ई उ ऊ ए ऐ ओ औ अं अः

a $\bar{a}$ i $\bar{i} \quad u \quad \bar{u}$ e ai $o$ au $\dot{m}$ ḥ

Transliteration (Romanization) of additional Nepali vowels:

ॠ ऋ लृ ल्छ

ri rī li li

Transliteration (Romanization) of Nepali consonants:

क ख ग घ ड च छ ज भ ज

ka kha ga gha ṅa cha chha ja jha ña
ट ठ ड ढ ण त थ द ध न

ța tha da dọa ṇa ta tha da dha na

प फ ब भ म य र ल व

pa pha ba bha ma ya ra la wa

श ष स ह क्ष त्र ज्ञ

sha șha sa ha kṣha tra gña

Transliteration (Romanization) of Nepali consonants - half form:

क ख् ग् घ् ड् च् छ ज् भु ज्

k kh g gh $\dot{n}$ ch chh j jh $\tilde{n}$

ट् ठ ड ढ़ ण् त् थ् द् ध् न्

$t$ th $d$ dh $n$th $d$ dh $n$

प् फ् ब् भ् म् य् र् ल् व्

p ph b' bh m y $r$ । w

शा ष् स् ह् क्ष् त्र ज्

sh șh $s$ h kșh tr gñ

Apart from letters presented above, there are some more letters in Nepali as presented below:

श्र ह अँ० अँ

shra hri om ă

Transliteration (Romanization) of Nepali numbers:

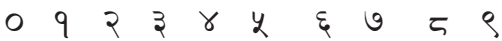

$\begin{array}{llllllllll}0 & 1 & 2 & 3 & 4 & 5 & 6 & 7 & 8 & 9\end{array}$

Transliteration (Romanization) of Nepali Barhakhari (example):

क का कि की कु क
ka kā ki ki ku kū
के कै को कौ कं क:
ke kai ko kau kan் kaḥ

ख खा खि खी खु खा

kha khā khi khī khu khū

खे खै खो खौ खं ख:

khe khai kho khau khan் khạ̣

ग गा गि गी गु गू

ga gā gi gī gu gû̀

गे गै गो गौ गं ग:

ge gai go gau gan் gaḥ

घ घा घि घी घु घू

gha ghā ghi ghī ghu ghū

घे घै घो घौ घं घ:

ghe ghai gho ghau ghan் ghạ

and so on. 


\section{REMARKS}

Nepali is not a simple language. Apart from vowels and consonants, it also has a few symbols applied with its letters to make a distinct sound. They are:

1. The dot (shirbindu) above the given alphabet is pronounced differently depending upon the consonant following it:

\begin{tabular}{|l|c|}
\hline \multicolumn{1}{|c|}{$\begin{array}{c}\text { Following } \\
\text { consonant }\end{array}$} & $\begin{array}{c}\text { Shirbindu } \\
\text { pronounced as }\end{array}$ \\
\hline Ka, Kha, Ga, Gha & $\dot{n}$ \\
\hline Cha, Chha, Ja, Jha & $\tilde{n}$ \\
\hline Ṭa, Tha, Da, Ḍha & $\underline{n}$ \\
\hline Ta, Tha, Da, Dha & $\mathrm{n}$ \\
\hline Others & $\dot{\mathrm{m}}$ \\
\hline
\end{tabular}

2. The sign " $"$ "written below a given consonant is pronounced as the sound of given consonant suffixed by 'ri' sound. Example कृ (Krị), प् (Pri).

3. The sign ", "written with a given consonant is pronounced as the sound of given consonant suffixed by 'ra' sound. Example क्र (Kra), प्र (Pra).

4. The sign " " called chandrabindu - a diacritic used in Devanagari script indicating that the previous vowel is nasalized.

5. In Nepali combined letters are formed by joining the half form of the consonants with the full form of consonants. The way these combined letters are written differs slightly in different cases.

6. Many names in Nepali are composed of two words. It is rational to separate these words. For example, Biratnagar should be written as Birat Nagar Lalitpur as Lalit Pur, Makawanpur as Makawan Pur. The last words in these names show some quality of the given place. The way we write the names must be standardize by the proposed "Geographical Names Authority".

\section{EXAMPLES:}

The following table shows some examples of Transliteration of Nepali names.

\begin{tabular}{|c|c|c|c|}
\hline S.N. & $\begin{array}{c}\text { NAME IN } \\
\text { DEVANAGARI }\end{array}$ & $\begin{array}{l}\text { NAME IN } \\
\text { ENGLISH }\end{array}$ & ROMANIZED \\
\hline 1 & काठमाडौं & Kathmadau & KĀṬHAMĀḌAUN \\
\hline 2 & काठमाण्डौ & Kathmandau & KĀṬHAMĀṆḌAU \\
\hline 3 & काठमाण्डू & Kathmandu & KĀṬHAMĀṆḌŪ \\
\hline 4 & ललित पुर & Lalit Pur & LALITA PURA \\
\hline 5 & बिराट नगर & Birat Nagar & BIRĀṬA NAGARA \\
\hline 6 & पोखरा & Pokhara & POKHARĀ \\
\hline 7 & वीर गज्ज & Birganj & WĪRA GAÑJA \\
\hline 8 & भक्त पुर & Bhakta Pur & BHAKTA PURA \\
\hline 9 & नेपाल गज्ज & Nepal Ganj & NEPĀLA GAÑJA \\
\hline 10 & लुम्बिनी & Lumbini & LUMBINĪ \\
\hline 11 & कपिलवस्तु & Kapilwastu & KAPILAWASTU \\
\hline 12 & नवल परासी & Nawal Parasi & NAWALA PARĀSī \\
\hline 13 & भैरहवा & Bhairahawa & BHAIRAHAWĀ \\
\hline 14 & धनकुटा & Dhankuta & DHANAKUṬA \\
\hline 15 & नारायण घाट & Narayan Ghat & NĀRĀYAṆA GHĀṬA \\
\hline 16 & कैलाली & Kailali & KAILĀLī \\
\hline 17 & बैतडी & Baitadi & BAITAḌ̄ \\
\hline 18 & ज्ञानेश्वर & Gyaneshwar & GÑ̄ĀNESHWARA \\
\hline 19 & वानेश्वर & Baneshwar & WANESHWARA \\
\hline 20 & धनगढी & Dhangadhi & DHANAGAḌHĪ \\
\hline 21 & रौतहट & Rautahat & RAUTAHAṬA \\
\hline
\end{tabular}

\section{RECOMMENDATIONS:}

We are used to write, especially the geographical names, the way we like it. In general we can recognize a name without serious confusion. So far nobody has raised the question why we write a name this or that way? But before it is too late we should develop a unique system of writing geographical names to avoid confusion, inconsistency, uncertainty and misunderstanding of these features among us and more importantly among international communities. We should not forget that most of the geographical names carry some historical and/or socio-cultural importance with them and it matters a lot.

National Planning Commission, Survey Department, Ministry of Local Development, General Post office, Election Commission etc are more concerned with geographical names in their day-to-day work. These organizations should therefore robustly work hand-in-hand to create, support and promote the idea of establishing a "Geographical Names Authority" in Nepal. 


\section{References:}

Lecture notes vol 1, DGSD - UNGEGN training course in toponymy, Enchede / Frankfurt am Main, August 10 - 24, 2002

Report On the Current Status Of United Nations Romanization Systems For GeographicalNames, Compiled by the UNGEGN Working Group on Romanization Systems, Version 3.0, November 2010

Romanization System for Nepali, BGN/PCGN 2009 Agreement, Available at: <http://earth-info.nga.mil/gns/ html/Romanization/Romanization_Nepali_v2011.pdf>, [accessed April 02, 2012]
Transliteration of Non-Roman Scripts, Available at: $<$ http://transliteration.eki.ee/>, [accessed April 15, 2012]

Transliteration System for Nepali - a document prepared by Survey Department for the preparation of topographic base maps at scales 1:25000 and 1:50000

Transliteration System for Nepali - a document prepared by Survey Department for the preparation of topographic base maps of Lumbini Zone at scales 1:25000

Wiktionary, the free dictionary, Available at: < $\underline{\mathrm{http}}: / /$ en.wiktionary.org/wiki/Wiktionary>, [accessed April 19, 2012]

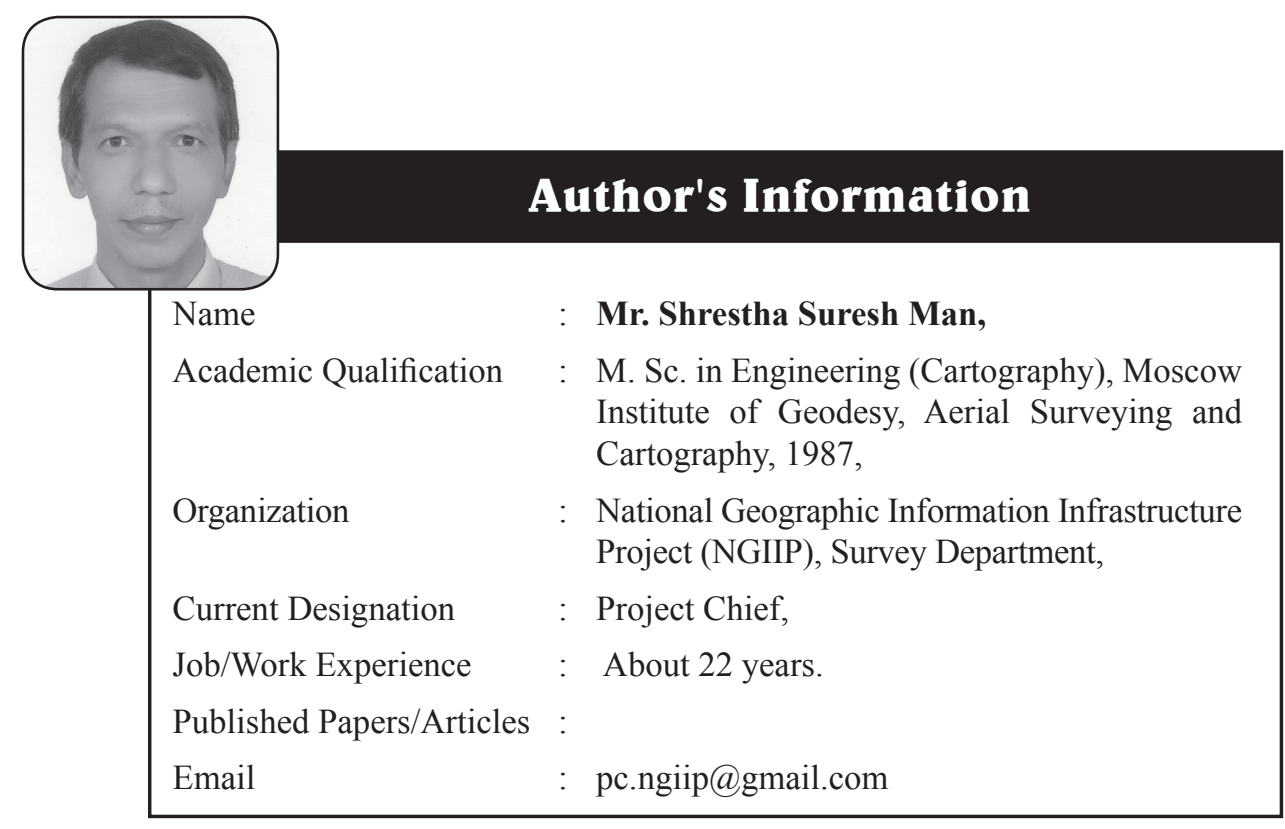

